\title{
Physical activity and subjective well-being in old age in Indonesia
}

\author{
Faiz Abdu Salam ${ }^{\text {abcd } *}$, Hari Yuliarto ${ }^{\text {bcd }}$, Elsa Ariestika ${ }^{\text {cde }}$ (i) \\ Universitas Negeri Yogyakarta, Indonesia
}

Received: 31 May 2021; Accepted 19 August 2021; Published 07 December 2021

Ed 2021; 6(3): 358-366

\begin{abstract}
Old age is characterized by many problems including physical health, psychological health, and overall wellbeing problems. Most studies indicate a decline in subjective well-being in the geriatric population. Although many studies have investigated the relationship between physical activity and subjective well-being in old age, few have been conducted among the aging Indonesian population. This study was aimed at investigating the association between physical activity and measures of subjective well-being among older adults in Indonesia using data from a community survey. After restricting the sample to individuals aged 60 and older, a sample of 1,813 old individuals was yielded. Two models of multiple regression were estimated. In the first model, subjective well-being was predicted by physical activity. The second model added to the first model a wide range of confounding variables in order to check whether the relationship between physical activity and subjective well-being was still significant after adjusting for covariates. The main findings revealed that staying physically active was associated with high levels of life satisfaction but not with happiness beyond the contribution of gender, education, marital status, religiosity, personality, and self-rated health. Physical activity yields well-being benefits in old age and these findings are relevant for policymakers, health professionals in the geriatric field, and public health professionals.
\end{abstract}

Keywords: Physical activity; happiness; life satisfaction

https://doi.org/10.25299/sportarea. 2021.vol6(3).6948

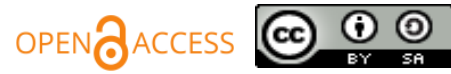

Copyright @ 2021 Faiz Abdu Salam, Hari Yuliarto, Elsa Ariestika

Corresponding Author: Faiz Abdu Salam, Department of Sport Science, Faculty of Sport Science, Universitas Negeri Yogyakarta, Yogyakarta, Indonesia

Email: faizabdusalam@gmail.com

How to Cite: Salam, F. A., Yuliarto, H., Ariestika, E. (2021). Physical activity and subjective well-being in old age in Indonesia, Journal Sport Area, 6(3), 358-366. https://doi.org/10.25299/sportarea. 2021.vol6(3).6948

Authors' Contribution: a - Study Design; b - Data Collection; c - Statistical Analysis; d - Manuscript Preparation; e - Funds Collection

\section{INTRODUCTION}

The enhanced life expectancy coupled with the decline in fertility has led to an increased aging population all around the world. Countries in the ASEAN region are not an exception. In fact, the population of older adults was estimated to be $8.1 \%$ in 2010 and is thought to be $17 \%$ in 2035 , and is projected to be $24.2 \%$ in 2050 (Adioetomo \& Mujahid, 2014). Indonesia being the fourth populous country in the world and the most populous in the ASEAN region will account for a large number of older adults. Indonesia had a population of 60 years of age as high as 21 million in 2010 and is estimated to have 62 million in 2050 (Biswas, 2018). Normally threshold from 60 years in age or more is referred to individuals as elderly. Reaching this age of life in the wake of extending life expectancy is to promote a high health-related quality of life into old age as a central concern for many. As asserted by (Mirtha, Tulaar, \& Pramantara, 2021), a 
longer life brings opportunities not only for older individuals and their families but rather than to the societies as a whole. These so-called additional years in the life shelf of humans may provide the chance to contribute in many ways to the families and communities as well. However, being healthy is all about the key success of these individuals. Corroborated with this later evidence, it is predictable that if people can experience these extra years of life in good health especially living in a supportive environment, their ability to perform things they value would be a little different from the younger person (Langhammer, Bergland, \& Rydwik, 2018; Mirtha et al., 2021). Sedentary lifestyles are common in many parts of the world, including Indonesia (Zeng et al., 2017). Despite the fact that physical activity is often recommended in later life due to its benefits to cardiovascular and cognitive health, osteoporosis (Clifford, Rahardjo, Bandelow, \& Hogervorst, 2014), it has also been proven to be favorable for muscle strength, aerobic capacity, reduction of fracture risk and general well-being in the elderly stage (Van der Bij, Laurant, \& Wensing, 2002; Christmas $\&$ Andersen, 2000). However, many of these free health benefits by involving in physical activity are not taken consciously by the elderly and are unexplored and untapped anyway. We recall for instance that in the United stated, over $60 \%$ of the elderly and are not regularly involved in such activities wherein other developed countries, $30 \%$ up to $80 \%$ of the elderly are physical inactivity (Van der Bij et al., 2002). For World Health Organization in its newest guideline for physical activity and sedentary behavior suggested that all adults have moderate-intensity for $150-300 \mathrm{~min}$ or vigorous-intensity for $75-150$ min per week (Mirtha et al., 2021). However, it has been reported by Indonesian Basic Health Research henceforth (RISKESDAS) 2018 that the proportion of low physical activity (less than 150 minutes per week) in Indonesia was estimated at 33,5\% with the highest number in Jakarta $(47,8 \%)$ and the lowest in Bali $(26 \%)$. In tandem, sufficient physical activity drop down from $73.9 \%$ to $66.5 \%$ in all age from 2013 to 2018 . With the same source, studies shown that 59\% of office workers in Jakarta are less active and spend time to do sedentary activity as much as 471 minutes per day or nearly 8 hours per day. The implication of these facts audited especially those related to the prevalence of physical activity in the Indonesian elderly imply that the low physical activity would indeed plague the well-being of these individuals or health problems such as obesity, and other ailments related to physical inactivity. Thus, due to the fact that physical activity is among crucial factors to keep elderly individual healthy, we gather our concerns to investigate the extent to which is the involvement of Indonesian olders in physical activity along with exploring main factors associated with subjective well-being within these elderly individuals.

Subjective well-being in old age can be viewed as a proxy of successful aging (Cho et al., 2015). Subjective well-being is defined with life evaluations which means the degree to which individuals think they are satisfied with their life and this is what Veenhoven (2012) calls life satisfaction or overall happiness. In fact, the term subjective well-being is usually used interchangeably with life satisfaction and happiness in the literature (Veenhoven, 2012). This approach of understanding well-being in terms of pleasure versus pain experienced by people is based on the principle of hedonism (Bramble, 2016). Subjective well-being is differently measured in the literature. Some scholars have sought to measure subjective well-being through a combination of life satisfaction, negative and positive affect (Diener, 1984). Other scholars have used a single item to measure subjective well-being (Helliwell, Huang, \& Wang, 2016). Single items are usually included in big social surveys like the European Social Survey, the World Values Survey, or even the Indonesia Family and Life Survey.

Many studies have addressed the benefits of staying physically active for subjective well-being. Wiese, Kuykendall, and Tay (2018) conducted a meta-analysis to assess the effect of leisure-time physical activity on subjective well-being. They found that staying physically active was associated with positive affect and life satisfaction. Others have reported that the duration and intensity also do matter. The study conducted by Wicker and Frick (2015) has revealed that the number of days people did moderate physical activity had a positive effect on their subjective well-being. In old age, this relationship seems to hold true as well. With a sample of older adults aged between 61 and 93, Parra-Rizo and Sanchis-Soler (2020) found that those older adults with high levels of physical activity reported higher scores in functional skill, functional autonomy, and subjective well-being. With a sample of community-dwelling old individuals, it was found that physical activity acted as a determinant of subjective well-being than did other biomarkers of health (Olsson, Hurtig- 
Wennlöf, \& Nilsson, 2014). Similarly, Won, Bae, Byun, and Seo (2020) conducted a meta-analytic study to investigate the psychological effects of physical activity among Korean older adults. They concluded that regular participation in physical activity yielded subjective well-being benefits. Compared to sedentary old individuals, it was found that older adults who were physically active had increased levels of subjective well-being in Taiwan (Ku, Fox, Chen, \& Chou, 2011).

The literature has sought to address the psychological impacts of staying physically active in old age. However, no studies, at least at our best of knowledge, have addressed this issue among the aging Indonesian population. Therefore, this study aimed to use nationally representative data from a community survey to address the relationship between physical activity and subjective wellbeing among older adults in Indonesia.

\section{METHOD}

This study used data from the Indonesia family life survey (IFLS). IFLS is an ongoing longitudinal socioeconomic and health survey that began in 1993 and until now has done 5 rounds (Strauss, Witoelar, \& Sikoki, 2016). The community survey represents around $83 \%$ of the entire Indonesian population. The survey provides information on individuals, their families, households, communities, education as well as on health (Strauss et al., 2016). During data collection, participants were informed about the goal and the outcome of the survey and gave their consent to participate, more documentation can be found in (Strauss et al., 2016). In this study, the fifth wave of the survey was used as it is the most recent wave available. The fifth wave collected information on 16,204 households and 50,148 individuals using multistage stratified sampling (Strauss et al., 2016). As we wanted to investigate subjective well-being benefits of being physically active in old age, the sample was restricted to individuals aged between 60 and 90 . These individuals' characteristics were selected based on existing pieces of literature that define all people whose age is 60 and over are considered to be named elderly persons (WHO, 2012). As far back as 1875, in Britain, the Friendly Societies Act ordained the profile of old age as any age after 50 for both genders. Yet pension schemes mostly used age 60 or 65 years for eligibility (Kowal, 2014). But the UN has not adopted a standard criterion, but generally uses 60+ years to refer to the older population (Marson, 2005; Singh \& Bajorek, 2014). Thus, this information audited above led us to identify and define inclusion criteria for the present research participants. After correcting missing data for subjective well-being variables, a sample of 1,813 older adults was yielded.

The dependent variable in this study was subjective well-being and was measured through scores of life satisfaction and happiness. For the life satisfaction variable, the survey asked respondents to think about their life as a whole and to estimate how satisfied they are with it (Strauss et al., 2016). The alternative answers ranged on a Likert scale from 1 point up to 5 points. The ranting scale 1-point stands for "not at all satisfied", 2 as an option means not satisfied, 3-point equal to impartial/neutral, 4-point stands for satisfied whereas 5-point option means very/completely satisfied). For the happiness variable/construct, the survey asked respondents to rate their level of happiness in the previous days on a Likert scale ranging from 1 (very unhappy), 2-point (unhappy), 3 (happy), and 4 (very happy).

While physical activity served as the independent variable in this study, the survey asked the following question: "think about the time you spent walking in the last seven days. This includes walking at work and at home, walking to travel from place to place, and any other walking that you might do solely for recreation, sport, exercise, or leisure, etc.. Did you do that for at least 10 min continuously?" (Strauss et al., 2016). The respondents who answered "yes" to this question were asked a subsequent question: "during the 7 days, how many days did you do that exercise?" (Strauss et al., 2016). Possible answers to this latter question ranged from 1 to 7 (Nizeyumukiza, Pierewan, Ndayambaje, \& Ayriza, 2021). High scores indicated a high frequency of physical activity and vice versa.

The literature has shown that gender (Graham \& Chattopadhyay, 2013; Nopiyanto, Raibowo, \& Prabowo, 2021), marital status (Cao, Krause, Saunders, \& Clark, 2015), education (Mrva, 2020) religiosity (Dilmaghani, 2017), personality (Lucas, 2018), social trust (Nizeyumukiza, Cilik Pierewan, Ndayambaje, \& 
Ayriza, 2020), and health (Ndayambaje, Pierewan, Nizeyumukiza, Nkundimana, \& Ayriza, 2020) are all related to subjective well-being. Therefore, these variables are susceptible to confound the relationship between physical activity and subjective well-being and will be controlled in this analysis.

As an analytical strategy, two models were estimated. The first model included physical activity in the analysis to estimate its relationship with life satisfaction and happiness. The second model added to model 1 the confounding variables to check whether physical activity was still an important predictor of life satisfaction and happiness after controlling for the confounding variables. The data management and analysis were performed in R statistical software (Fox \& Leanage, 2016).

\section{RESULTS AND DISCUSSION}

The descriptive statistics can be found in Table 1. The mean score was 3.24 for life satisfaction, 2.93 for happiness, 5.34 for physical activity, 7.01 for extroversion, and 2.90 for social trust. The percentage of female respondents was 49.9 , more than $65 \%$ were married, around $72 \%$ had completed primary education, about $13 \%$ had completed junior high school, around $10 \%$ had completed senior high education, and slightly over 3\% had completed high education. Around $90 \%$ reported that they were religious and about $64 \%$ were healthy.

Table 1. Summary of study variables and the prevalence Subjective Well-Being $(\mathbf{n}=\mathbf{1 , 8 1 3})$

\begin{tabular}{|c|c|c|c|c|c|c|}
\hline Study variables & $n$ & $\%$ & Mean (SD) & Mean of LS (SD) & Mean of Hap (SD) & Range \\
\hline Life satisfaction & 1,813 & & $3.24(0.82)$ & & & $1-5$ \\
\hline Happiness & 1,813 & & $2.93(0.49)$ & & & $1-4$ \\
\hline Physical activity & 1,595 & & $5.34(2.23)$ & & & $1-7$ \\
\hline Extroversion & 1,813 & & $7.01(1.33)$ & & & $2-10$ \\
\hline Social trust & 1,813 & & $2.90(1.18)$ & & & $1-4$ \\
\hline \multicolumn{7}{|l|}{ Gender } \\
\hline Female & 905 & 49.9 & & $3.28(0.79)$ & $2.94(0.49)$ & $1-5$ \\
\hline Male & 908 & 50.1 & & $3.23(0.81)$ & $2.96(0.46)$ & $1-5$ \\
\hline \multicolumn{7}{|l|}{ Marital status } \\
\hline Married & 1,224 & 67.5 & & $3.27(0.78)$ & $2.98(0.46)$ & $1-5$ \\
\hline Unmarried & 589 & 32.5 & & $3.22(0.85)$ & $2.87(0.53)$ & $1-5$ \\
\hline \multicolumn{7}{|l|}{ Education } \\
\hline Primary & 999 & 72.7 & & $3.21(0.83)$ & $2.94(0.49)$ & $1-5$ \\
\hline Junior high school & 179 & & 13.02 & $3.35(0.71)$ & $2.97(0.45)$ & $1-5$ \\
\hline Senior high school & 150 & 10.9 & & $3.35(0.69)$ & $3.02(0.39)$ & $1-5$ \\
\hline High education & 46 & 3.34 & & $3.41(0.71)$ & $3.08(0.35)$ & $1-5$ \\
\hline \multicolumn{7}{|l|}{ Self-rated health } \\
\hline Healthy & 1,172 & 64.5 & & $3.33(0.78)$ & $3.01(0.44)$ & $1-5$ \\
\hline Unhealthy & 641 & 35.5 & & $3.09(0.83)$ & $2.83(0.52)$ & $1-5$ \\
\hline \multicolumn{7}{|l|}{ Religious } \\
\hline Yes & 1,255 & 90.2 & & $3.23(0.79)$ & $2.94(0.45)$ & $1-5$ \\
\hline No & 136 & 9.8 & & $3.05(0.79)$ & $2.89(0.50)$ & $1-5$ \\
\hline
\end{tabular}

The results of the multivariate analysis can be found in Table 2. Model 1 indicated that physical activity was positively associated with life satisfaction $(\beta=0.01, \mathrm{p}<0.05)$, but not with happiness $(\beta=0.00, \mathrm{p}>0.05)$. Model 2 shows the results of the multivariate regression after including confounding variables in the analysis. The results showed that even after controlling confounding variables, physical activity was still positively related to life satisfaction $(\beta=0.02, \mathrm{p}<0.05)$, but not with happiness $(\beta=0.00, \mathrm{p}>0.05)$.

Most the control variables exhibited a significant association with life satisfaction and happiness. Being healthy was associated with increased levels of life satisfaction $(\beta=0.17, p<0.01)$ and happiness $(\beta=0.16, p$ $<0.001)$. Having completed junior and senior high school was associated with life satisfaction $(\beta=0.20, \mathrm{p}<$ 0.01 and $\beta=0.24, p<0.01$ respectively), and only having completed senior high school was positively associated with happiness $(\beta=0.09, \mathrm{p}<0.05)$. Finally, religiosity and extroversion were positively related to 
life satisfaction $(\beta=0.17, \mathrm{p}<0.05$ and $\beta=0.05, \mathrm{p}<0.01$ respectively), and extroversion personality trait was also positively related to happiness $(\beta=0.02, \mathrm{p}<0.05)$.

Table 2. Results of the Multivariate Regression Predicting Subjective Well-Being

\begin{tabular}{|c|c|c|c|c|c|c|c|c|}
\hline \multirow{3}{*}{ Variables } & \multicolumn{4}{|c|}{ Life Satisfaction } & \multicolumn{4}{|c|}{ Happiness } \\
\hline & \multicolumn{2}{|c|}{ Model 1} & \multicolumn{2}{|c|}{ Model 2} & \multicolumn{2}{|c|}{ Model 1} & \multicolumn{2}{|c|}{ Model 2} \\
\hline & Coef. & SE & Coef. & SE & Coef. & SE & Coef. & SE \\
\hline Intercept & $3.15 * * *$ & 0.05 & $2.44 * * *$ & 0.18 & $2.90 * * *$ & 0.03 & $2.64 * * *$ & 0.11 \\
\hline Physical activity & $0.01 *$ & 0.008 & $0.02 *$ & 0.01 & 0.006 & 0.009 & 0.005 & 0.006 \\
\hline \multicolumn{9}{|l|}{ Gender (ref. female) } \\
\hline Male & & & -0.06 & 0.05 & & & 0.01 & 0.03 \\
\hline \multicolumn{9}{|l|}{ SRH (ref. unhealthy) } \\
\hline Healthy & & & $0.17 * *$ & 0.05 & & & $0.16 * * *$ & 0.03 \\
\hline \multicolumn{9}{|l|}{ Marital status (ref. unmarried) } \\
\hline Married & & & -0.05 & 0.06 & & & 0.04 & 0.03 \\
\hline \multicolumn{9}{|l|}{ Education (ref. primary) } \\
\hline Junior high school & & & $0.20 * *$ & 0.07 & & & 0.03 & 0.04 \\
\hline Senior high school & & & $0.24 * *$ & 0.07 & & & $0.09 *$ & 0.05 \\
\hline High education & & & 0.09 & 0.12 & & & 0.07 & 0.07 \\
\hline Social trust & & & 0.009 & 0.02 & & & -0.01 & 0.01 \\
\hline \multicolumn{9}{|l|}{ Religious (ref. non-religious) } \\
\hline Religious & & & $0.17 *$ & 0.08 & & & -0.00 & 0.05 \\
\hline Extroversion & & & $0.05 * *$ & 0.01 & & & $0.02 *$ & 0.01 \\
\hline R-Squared & 0.002 & & 0.03 & & 0.001 & & 0.03 & \\
\hline
\end{tabular}

The aim of this study was to investigate the association between physical activity and measures of subjective well-being among older adults using nationally representative data from a community survey. The main findings revealed a positive association between physical activity and life satisfaction but not with happiness. However, the effects were quite small, smaller than those reported in previous studies. This is might be due to cultures differences. Although the association between physical activity and well-being seems to be generalizable across cultures (Wiese et al., 2018), this may not apply to some cultures. In Korea for example, physical activity in elderly was not an established culture, where older people were marginalized to access sport due to urbanization, population migration, and socio-economic marginalization (Park, 2017), and Won et al., (2020) concluded that the effect of physical activity on the well-being in the elderly might be different across cultures. In Indonesia also, previous research has reported that physical activity was not a culture in the elderly. In fact, a study reported that more than $70 \%$ of the surveyed elderly in Indonesia had watching television as main activity, and only less than $2 \%$ were participating in outdoor or physical activities (Arifin, Braun, \& Hogervorst, 2012). Comparative studies might inform better about culture differences in the association between physical activity and well-being of people.

Although the effects in this study were small, the findings corroborate prior studies about the benefits of physical activity for subjective well-being in old age (Parra-Rizo \& Sanchis-Soler, 2020; Won et al., 2020). Those respondents who were doing physical activity regularly were more satisfied with their life. Several mechanisms can help explain this relationship. Physiologically, physical activity facilitates the secretion of endorphins and this process creates feelings of calmness and good mood (Basso \& Suzuki, 2017). Moreover, it is thought that regular physical activity allows the synaptic transmission of amines which has antidepressant effects (Phillips \& Fahimi, 2018). Furthermore, using a multilevel approach, it was found that physical activity was associated with a reduced level of depression (Nizeyumukiza et al., 2021). At the cognitive level, physical activity is thought to enhance cognitive processes (Giorgio, Kuvacic, Milic, \& Padulo, 2018). Socialization is another explanation of the positive relationship of physical activity with subjective well-being (Sari, 2016). In fact, it is believed that physical activity enhances social relationships by providing a ground to socialize with peers and exchange social support (Smith, Banting, Eime, Sullivan, 
\& Uffelen, 2017). Psychologically, because physical activity provides individuals with challenges, overcoming them brings a sense of mastery and increased self-efficacy (Rajati et al., 2014).

The other interesting findings concern confounding variables that exhibited significant association with subjective well-being. This study found that old individuals who had a junior high school education were more satisfied with their life than those with primary education (Widiyatmoko \& Hadi, 2018). Older adults with senior high school education were more satisfied and were happier than those with primary education. This corroborates prior studies that found positive effects of education on subjective well-being (Kuroki, 2011). As expected, self-rated health was an important predictor of both happiness and life satisfaction, which corroborate the findings of previous studies (Nizeyumukiza et al., 2020). Extroverted people were more satisfied with life and happier than their counterparts. This corroborates prior studies that found a positive relationship between extroversion personality traits and subjective well-being in Indonesia (Ndayambaje et al., 2020). Religious people reported being more satisfied with life than their counterparts which is in line with previous studies (Dilmaghani, 2017; Nizeyumukiza et al., 2020).

\section{CONCLUSION}

Nearly all geriatric people can derive health benefits from improving their level of physical activity and subsequently betterment the well-being in their lifespan. This study reveals noteworthy insight into involving in physical activity, especially during old ages. We look back on here that this study sought to investigate the association between physical activity and subjective well-being in old age using data from a community survey. Even though some current works of literature employ happiness and life satisfaction to be used interchangeably to represent subjective well-being, apart from physical activity, this study found that different factors could influence the well-being of the elderly person as a whole. Gender and social capital have different influences on happiness/well-being and life satisfaction. The findings suggest that staying physically active in old age might be yield well-being benefits. Subjective well-being is an indicator of successful aging and given the expected increased aging population in Indonesia. In addition, the study found that being healthy, and frequently/regularly doing physical activity are associated with better mental health and well-being in old age; therefore, present findings are relevant for policymakers, health professionals in the geriatrics, and public health professionals to take into account these characteristics when designing, promoting preventions and interventions in those elderly citizens. Shortly, maintenance of increased physical activity level needs to be improved, as ongoing participation is necessary to sustain health benefits for advanced people in age. More attention should be given to the development and implementation of more intense and tailored interventions that include policy, environmental and behavioural support. As limitations, this study has some limitations that have to be acknowledged. The data used are cross-sectional and cannot be used to draw causal effects. To this end, longitudinal might bring better insights. The strength of the study resides in the national scope of the data. Moreover, the study accounted for a great number of confounding variables that should be controlled in further study.

\section{ACKNOWLEDGMENT}

This study used secondary data from the fifth wave of the Indonesia Family Survey conducted by RAND Corporation (http://www.rand.org/labor/FLS/IFLS.html). We are thankful to this organization who provided free access to the data and grateful to the Indonesian respondents who answered the survey.

\section{CONFLICT OF INTEREST}

The authors declare no conflicts of interest associated with this manuscript. We know of no conflicts of interest associated with this publication, and there has been no significant financial support for this work that could have influenced its outcome. As corresponding author, I confirm that the manuscript has been read and approved for submission by all the named authors. 


\section{REFERENCES}

Adioetomo, S. M., \& Mujahid, G. (2014). 'Indonesia on the threshold of population ageing', UNFPA Indonesia Monograph Series: No.1.

Arifin, E. N., Braun, K. L., \& Hogervorst, E. (2012). Three Pillars of Active Ageing in Indonesia. Asian Population Studies, 8(2). https://doi.org/10.1080/17441730.2012.680334

Basso, J. C., \& Suzuki, W. A. (2017). The Effects of Acute Exercise on Mood, Cognition, Neurophysiology, and Neurochemical Pathways: A Review. Brain Plasticity, 2, 127-152. https://doi.org/10.3233/BPL160040

Biswas, S. (2018). Spotlight on retirement: Indonesia. Retrieved from https://www.soa.org/globalassets/assets/Files/resources/research-report/2018/spotlight-retirementindonesia.pdf

Bramble, B. (2016). A New Defense of Hedonism about Well-Being. Ergo, an Open Access Journal of Philosophy, 3(20201214), 85-112. https://doi.org/10.3998/ergo.12405314.0003.004

Cao, Y., Krause, J. S., Saunders, L. L., \& Clark, J. M. R. (2015). Impact of marital status on 20-year subjective well-being trajectories. Topics in Spinal Cord Injury Rehabilitation, 21(3), 208-217. https://doi.org/10.1310/sci2103-208

Cho, J., Martin, P., Poon, L. W., Jazwinski, S. M., Robert, C. G., Marla, G., ... Davey, A. (2015). Successful aging and subjective well-being among oldest-old adults. Gerontologist, 55(1), 132-143. https://doi.org/10.1093/geront/gnu074

Christmas, C., \& Andersen, R. A. (2000). Exercise and older patients: Guidelines for the clinician. Journal of the American Geriatrics Society, 48(3), 318-324. https://doi.org/10.1111/j.15325415.2000.tb02654.x

Clifford, A., Rahardjo, T. B., Bandelow, S., \& Hogervorst, E. (2014). A cross-sectional study of physical activity and health-related quality of life in an elderly Indonesian cohort. 77(September), 451-456. https://doi.org/10.4276/030802214X14098207541036

Diener, E. (1984). Subjective Well-Being. Psychological Bulletin, 95(3), 542-575.

Dilmaghani, M. (2017). Religiosity and Subjective Wellbeing in Canada. Journal of Happiness Studies. https://doi.org/10.1007/s10902-016-9837-7

Fox, J., \& Leanage, A. (2016). R and the Journal of Statistical Software. Journal of Statistical Software, 73(2). https://doi.org/10.18637/jss.v073.i02

Giorgio, A. De, Kuvacic, G., Milic, M., \& Padulo, J. (2018). The Brain and Movement: How Physical Activity Affects the Brain. Montenegrin Journal of Sports Science and Medicine, 7(2), 63-68. https://doi.org/10.26773/mjssm.180910

Graham, C., \& Chattopadhyay, S. (2013). Gender and Well-Being around the World. International Journal of Happiness and Development, 1(2), 212-232.

Helliwell, J. F., Huang, H., \& Wang, S. (2016). New Evidence on Trust and Well-Being (No. 22450). Retrieved from http://www.nber.org/papers/w22450

Kowal, P. (2014). Defining “ Old Age .” (August). https://doi.org/10.13140/2.1.2055.4885

Ku, P. O. W., Fox, K. R., Chen, L. I. J., \& Chou, P. (2011). Physical activity, sedentary time and subjective well-being in Taiwanese older adults. International Journal of Sport Psychology, 42(3), 245-262.

Kuroki, M. (2011). Does Social Trust Increase Individual Happiness in Japan. The Japanese Economic Review, 62(4), 444-459. https://doi.org/10.1111/j.1468-5876.2011.00533.x 
Langhammer, B., Bergland, A., \& Rydwik, E. (2018). The Importance of Physical Activity Exercise among Older People. BioMed Research International, 2018, 13-15. https://doi.org/10.1155/2018/7856823

Lucas, R. E. (2018). Exploring the Associations Between Personality and Subjective Well-Being. In E. Diener, S. Oishi, \& L. Tay (Eds.), Handbook of well-being. https://doi.org/nobascholar.com

Marson, A. (2005). United nations expert group meeting on social and economic implications of changing population age structures. Population (English Edition), 31(1), 81-101.

Mirtha, L. T., Tulaar, A., \& Pramantara, I. D. P. (2021). Towards Healthy Aging with Physical Activity and Nutrition. Amerta Nutrition, 4(1SP), 15. https://doi.org/10.20473/amnt.v4i1sp.2020.15-20

Mrva, M. (2020). Social capital and subjective well-being in slovakia. Sociologia (Slovakia), 52(2), 111131. https://doi.org/10.31577/sociologia.2020.52.2.5

Ndayambaje, E., Pierewan, A. C., Nizeyumukiza, E., Nkundimana, B., \& Ayriza, Y. (2020). Marital Status and Subjective Well-Being: Does Education Level Take into Account? Cakrawala Pendidikan, 39(1), 120-132. https://doi.org/10.21831/cp.v39i1.29620

Nizeyumukiza, E., Cilik Pierewan, A., Ndayambaje, E., \& Ayriza, Y. (2020). Trust and well-being: Evidence from Indonesia. Asian Social Work and Policy Review, 14(3), 148-157. https://doi.org/10.1111/aswp.12205

Nizeyumukiza, E., Pierewan, A. C., Ndayambaje, E., \& Ayriza, Y. (2021). Social Capital and Mental Health among Older Adults in Indonesia: A Multilevel Approach. Journal of Population and Social Studies, 29, 1-14. https://doi.org/10.25133/jpssv292021.001

Nopiyanto, Y. E., Raibowo, S., \& Prabowo, G. U. (2021). Psychological characteristics of athletes at Pusat Pendidikan dan Latihan Pelajar (PPLP) in Bengkulu. Journal of Sport Area, 6(1), 37-43. https://doi.org/10.25299/sportarea.2021.vol6(1).5572

Olsson, L. A., Hurtig-Wennlöf, A., \& Nilsson, T. (2014). Subjective well-being in Swedish active seniors and its relationship with physical activity and commonly available biomarkers. Clinical Interventions in Aging, 9, 1233-1239. https://doi.org/10.2147/CIA.S63198

Park, C. H. (2017). Experience of sport stacking in Korean older adults. Journal of Exercise Rehabilitation, 13(1), 43-47. https://doi.org/10.12965/jer.1734922.461

Parra-Rizo, M. A., \& Sanchis-Soler, G. (2020). Satisfaction with life, subjective well-being and functional skills in active older adults based on their level of physical activity practice. International Journal of Environmental Research and Public Health, 17(4), 1299. https://doi.org/10.3390/ijerph17041299

Phillips, C., \& Fahimi, A. (2018). Immune and Neuroprotective Effects of Physical Activity on the Brain in Depression. Frontiers in Neuroscience, 12(July), 1-22. https://doi.org/10.3389/fnins.2018.00498

Rajati, F., Sadeghi, M., Feizi, A., Sharifirad, G., Hasandokht, T., \& Mostafavi, F. (2014). Self-efficacy strategies to improve exercise in patients with heart failure: A systematic review. ARYA Atherosclerosis, 10(6), 319-333.

RISKESDAS. (2018). Laporan Hasil Riset Kesehatan Dasar (Riskesdas). Badan Litbangkes Kementerian Kesehatan RI.

Sari, M. (2016). Kontribusi Lingkungan Keluarga dan Aktivitas Fisik Terhadap Kesegaran Jasmani Anak Tunagrahita. Journal Sport Area, 1(1), 38-46. https://doi.org/10.30814/sportarea.v1i1.374

Singh, S., \& Bajorek, B. (2014). Defining "elderly" in clinical practice guidelines for pharmacotherapy. Pharmacy Practice (Internet), 12(4), 0-0. https://doi.org/10.4321/s1886-36552014000400007 
Smith, G. L., Banting, L., Eime, R., Sullivan, G. O., \& Uffelen, J. G. Z. Van. (2017). The association between social support and physical activity in older adults : a systematic review. International Journal of Behavioral Nutrition and Physical Activity, 14, 56. https://doi.org/10.1186/s12966-017-0509-8

Strauss, J., Witoelar, F., \& Sikoki, B. (2016). User's Guide for the Indonesia Family Life Survey, Wave 5 (Vol. 2). Retrieved from https://www.rand.org/pubs/working_papers/WR1143z2.html.

Van der Bij, A., Laurant, M. G. H., \& Wensing, M. (2002). Effectiveness of Physical Activity A Review. American Journal of Preventive Medicine, 22(2), 120-133. https://doi.org/10.1016/S07493797(01)00413-5

Veenhoven, R. (2012). Happiness, Also Known as "Life Satisfaction" and "Subjective Well-Being." In K. Land, A. Michalos, \& J. M. Sirgy (Eds.), Handbook of Social Indicators and Quality of Life Research. https://doi.org/10.1007/978-94-007-2421-1_3

WHO. (2012). Definition of an older or elderly person: Proposed Working Definition of an Older Person in Africa for the MDS ProjectNo Title. World Health Organisation, (August). https://doi.org/10.13140/2.1.5188.9286

Wicker, P., \& Frick, B. (2015). The relationship between intensity and duration of physical activity and subjective well-being. European Journal of Public Health, 25(5), 868-872. https://doi.org/10.1093/eurpub/ckv131

Widiyatmoko, F., \& Hadi, H. (2018). Tingkat Aktivitas Fisik Siswa di Kota Semarang. Journal Sport Area, 3(2), 140-147. https://doi.org/10.25299/sportarea.2018.vol3(2).2245

Wiese, C. W., Kuykendall, L., \& Tay, L. (2018). Get active? A meta-analysis of leisure-time physical activity and subjective well-being. Journal of Positive Psychology, 13(1), 57-66. https://doi.org/10.1080/17439760.2017.1374436

Won, D., Bae, J. S., Byun, H., \& Seo, K. B. (2020). Enhancing subjective well-being through physical activity for the elderly in Korea: A meta-analysis approach. International Journal of Environmental Research and Public Health, 17(1). https://doi.org/10.3390/ijerph17010262

Zeng, N., Ayyub, M., Sun, H., Wen, X., Xiang, P., \& Gao, Z. (2017). Effects of Physical Activity on Motor Skills and Cognitive Development in Early Childhood: A Systematic Review. 2017. https://doi.org/10.1155/2017/2760716 